\title{
Does neighborhood environment influence girls' pubertal onset? findings from a cohort study
}

\author{
Julianna Deardorff ${ }^{*}$, Molly Fyfe ${ }^{1}$, J Paul Ekwaru', Lawrence H Kushi ${ }^{2}$, Louise C Greenspan ${ }^{2}$ and Irene H Yen ${ }^{3}$
}

\begin{abstract}
Background: Pubertal onset occurs earlier than in the past among U.S. girls. Early onset is associated with numerous deleterious outcomes across the life course, including overweight, breast cancer and cardiovascular health. Increases in childhood overweight have been implicated as a key reason for this secular trend. Scarce research, however, has examined how neighborhood environment may influence overweight and, in turn, pubertal timing. The current study prospectively examined associations between neighborhood environment and timing of pubertal onset in a multi-ethnic cohort of girls. Body mass index (BMI) was examined as a mediator of these associations.
\end{abstract}

Methods: Participants were 213 girls, 6-8 years old at baseline, in an on-going longitudinal study. The current report is based on 5 time points (baseline and 4 annual follow-up visits). Neighborhood environment, assessed at baseline, used direct observation. Tanner stage and anthropometry were assessed annually in clinic. Survival analysis was utilized to investigate the influence of neighborhood factors on breast and pubic hair onset, with BMI as a mediator. We also examined the modifying role of girls' ethnicity.

Results: When adjusting for income, one neighborhood factor (Recreation) predicted delayed onset of breast and pubic hair development, but only for African American girls. BMI did not mediate the association between Recreation and pubertal onset; however, these associations persisted when BMI was included in the models.

Conclusions: For African American girls, but not girls from other ethnic groups, neighborhood availability of recreational outlets was associated with onset of breast and pubic hair. Given the documented risk for early puberty among African American girls, these findings have important potential implications for public health interventions related to timing of puberty and related health outcomes in adolescence and adulthood.

\section{Background}

Early puberty is associated with numerous negative mental health and physical health outcomes over the life course for girls and women, including obesity, type II diabetes, depression, conduct problems, substance use, teen pregnancy, and breast and other reproductive cancers [1-7]. Timing of pubertal onset among girls varies widely, with secondary sexual characteristics - the first observable signs of puberty - usually appearing around ages 10 to 11 years $[8,9]$. However, epidemiologic evidence confirms that certain pubertal markers are occurring earlier among girls in the U.S. than in the past, particularly onset of breast and pubic hair development $[8,10-12]$. In addition, there are marked disparities in pubertal timing across ethnic groups.

\footnotetext{
* Correspondence: jdeardorff@berkeley.edu

${ }^{1}$ School of Public Health, University of California, Berkeley, CA, USA

Full list of author information is available at the end of the article
}

Recent epidemiological research shows that at age 8 years approximately $43 \%$ of black girls, $31 \%$ of Hispanic girls and $18 \%$ of white girls have experienced onset of breast development [13].

This documented trend of earlier pubertal onset has prompted a cascade of research focused on potential antecedents that may explain variability in girls' timing of puberty. A variety of environmental and genetic factors have been identified that influence pubertal timing [14] with a recent enhanced focus on behavioral and environmentally-related factors, including overweight and obesity [15], family stressors [16-19], and environmental toxins [20] as potentially important determinants. No known studies, however, have examined the influence of neighborhood factors, nor how neighborhood effects might operate through girls' overweight, to influence
C Biomed Central

(c) 2012 Deardorff et al; licensee BioMed Central Ltd. This is an Open Access article distributed under the terms of the Creative Commons Attribution License (http://creativecommons.org/licenses/by/2.0), which permits unrestricted use, distribution, and reproduction in any medium, provided the original work is properly cited. 
pubertal onset. The current study addresses these gaps in the scientific literature.

Neighborhoods are complex entities encompassing culture, economics, history, governance, and the built and natural environments [21]. The neighborhoods in which children live have been shown to influence their behaviors and health outcomes [22-27]. There are conceivably two potential pathways through which a neighborhood environment might influence a girl's pubertal timing: (1) through reduced access to healthful foods and physical activity, which may lead to overweight and, in turn, earlier pubertal onset, and (2) through exposure to acute and chronic stress, which may trigger hormonal stress responses that prompt pubertal onset. An extensive body of literature supports the first proposed pathway. Research shows that body composition and physical activity levels are influenced by neighborhood environments and are also related to timing of girls' pubertal development [25,27-33]. Limited availability of fresh foods and poor access to safe recreational outlets may negatively influence girls' eating habits and physical activity patterns, which can lead to overweight and increased adiposity. In turn, hormonal changes related to increases in adiposity can subsequently accelerate pubertal maturation [34]. In addition, ample research suggests that exposure to stressful environmental conditions, particularly within the family realm, confers risk for earlier pubertal development [14] ostensibly by influencing hormonal pathways that trigger puberty [19]. As such, neighborhood stressors may operate in a similar manner to stress in the family and directly influence pubertal maturation. A combination of these two pathways may also exist, whereby neighborhood stressors and poor psychological functioning lead to emotional eating, reduced physical activity and overweight, which in turn may promote earlier puberty.

Past studies examining environmental determinants of pubertal timing have exhibited methodological limitations. One such limitation is that many studies have focused on menarche as an outcome, which occurs relatively late in the pubertal transition. Other studies have examined overall pubertal development without distinguishing between onset of breast development (thelarche) and onset of pubic hair (pubarche) development. Thelarche and pubarche represent observable markers of underlying hormones that are dependent on the maturation of unique endocrine axes, i.e., the hypothalamic-pituitary-gonadal (HPG) and hypothalamic-pituitary-adrenal (HPA) axis, respectively. Neighborhood factors might conceivably act on these hormonal pathways differentially. For instance, neighborhood conditions that lead to increases in body fat, which is associated with estrogen production, are likely to trigger the HPG axis resulting in accelerated breast development. Alternatively, environmental stress and resulting cortisol release (a measure of stress response) may awaken the HPA axis and accelerate pubic hair development $[19,35]$. As such, it is important to examine these early pubertal markers (thelarche and pubarche) separately in an effort to better understand potential hormonal responses to neighborhood environments. Moreover, these systems may play differential roles in the etiology of downstream health outcomes, such as breast cancer and other reproductive cancers.

In addition to the aforementioned limitations, studies of environmental determinants of pubertal onset have often been limited by study design. Many were cross-sectional, therefore limiting causal inference. Of those that were longitudinal, often participants were recruited after pubertal onset occurred, i.e., when girls were already peri-pubertal. As such, there is a need for longitudinal research that recruits girls at younger ages and follows them through the pubertal transition.

The current study aims to address these gaps in the extant literature. We utilized 5 waves of data from a larger ongoing study of ethnically-diverse girls and their parents/ caregivers. Using direct observations of neighborhood environment and clinic-based Tanner stage assessments, we investigated the contribution of neighborhood factors to timing of onset of breast and pubic hair development, while adjusting for family income. Because girls and their families may be differentially affected by their neighborhoods depending on their contextual and cultural backgrounds, we also examined the modifying (moderating) effect of girls' ethnicity on the associations between neighborhood factors and pubertal outcomes. Moreover, in order to understand potential mechanisms, we investigated whether BMI operated in the causal pathway (i.e., mediated the relationship) between neighborhood factors and onset of puberty.

\section{Methods}

\section{Participants and procedure}

This project was carried out as part of the NIEHS/NCI Breast Cancer and the Environment Research Centers, four centers with transdisciplinary research collaborations across biologic, epidemiologic, and community outreach projects [36]. The present investigation focused on one epidemiologic project, the Cohort Study of Young Girls' Nutrition, Environment, and Transitions (CYGNET). The CYGNET study began in 2005 when 444 6-8-year-old girls and their primary caregivers (over $90 \%$ biological mothers) were recruited from the Kaiser Permanente Northern California (KPNC) health plan membership. Eligible members were identified through the KPNC Infant Cohort File, a database containing information on all live births occurring in KPNC facilities or to KPNC members. Details of 
the CYGNET study are described elsewhere [18,37]. Study procedures were approved by the Kaiser Permanente and UCSF Institutional Review Boards.

Participants for the current report $(n=213)$ were randomly sampled from the 444 participating families in the larger study. We focused on the first 5 data collection points (baseline and 4 annual follow-up visits) from this ongoing longitudinal study. Girls were 6-8 years old at baseline and 10-12 years old at last follow-up assessment for the current investigation. Intervals between participants' clinic visits were approximately one year, depending on the family's scheduling needs, and every effort was made to schedule within 1-2 months of one year. At baseline, informed assent and consent were obtained from participating girls and their caregivers, respectively. At each annual clinic visit, girls' anthropometric measurements and Tanner staging for breast and pubic hair development were assessed in clinic by trained researchers. Interviews were conducted with caregivers to collect additional information, including demographics. Neighborhood environment data were collected for this subsample of 213 participants through in-person street observation.

\section{Measures}

\section{Pubertal onset}

Pubertal onset was assessed by clinical exam using the 5stage Tanner staging system, which is widely utilized to describe the onset and progression of pubertal changes $[38,39]$. Assessment of Tanner stage for breast and pubic hair development was conducted at each annual clinic visit by rigorously trained research assistants under the supervision of a pediatric endocrinologist. Stage of breast development was assessed by visual inspection and palpation, and stage of pubic hair development was assessed by visual inspection. Onset of breast and pubic hair development were coded separately as: "no onset" (Stage 1) or "onset" (Stage 2 or above).

\section{Neighborhood environment}

Direct observations of girls' neighborhoods were conducted using a modified version of the St. Louis Audit Tool [40]. Audit tool items fit into five categories: land use environment, transportation environment, facilities, park or playground contents, and physical disorder. Street observers were provided a map with a circle representing a quarter-mile radius drawn around each girl's residence. Details of the direct observation method and resultant scales are described elsewhere [37]. A rigorous factor analysis resulted in five neighborhood scales: 1) mixed residential and commercial (included two-, three-, four-family homes ("walk-ups"); apartment building/complex; presence of sidewalks; place of worship; community center; day care or preschool; convenience or small grocery store); 2) food and retail (included chain fast food restaurant; supermarket; other convenience food restaurant; laundry or dry cleaners; full-service restaurant; coffee shop); 3) recreation (included park; walking or hiking trails; sports/playing field, basketball courts or tennis courts); 4) walkability (included street shoulders or wide outside lanes; curb bulb out/curb extension; traffic circle/roundabout); and 5) physical disorder (included garbage, litter, or broken glass in sidewalks or streets; graffiti on buildings) [37]. Cronbach's alphas for the neighborhood scales ranged from 0.50 to 0.87 . A higher score in any of the indices indicated a greater presence of those attributes in a girl's neighborhood environment. For example a higher score in the 'food and retail' indices would indicate greater presence of fast food outlets, convenience stores and/or retail food outlets.

\section{Ethnicity}

Girl's ethnicity was assessed using primary caregiver's report at baseline and was coded as non-Hispanic White, African American or Black, Hispanic or Latino, Asian American, or Other.

\section{Family income}

Caregivers reported annual family income at baseline. Income categories were: < \$25,000; $\$ 25,000-\$ 49,999$; $\$ 50,000-\$ 74,999 ; \$ 75,000-\$ 99,999 ; \geq \$ 100,000$. Income was dichotomized into "lower" $(<\$ 50 \mathrm{~K} /$ year $)$ and "higher" (> \$50 k/year) income.

\section{Body mass index (BMI)}

Height and weight measurements were obtained in clinic using calibrated scales and fixed stadiometers. Measurements at baseline were used to calculate BMI as weight $(\mathrm{kg}) /(\text { height }(\mathrm{m}))^{2}$. BMI values were standardized for age and percentiles and z-scores calculated, using methods and standard distributions as provided by the Centers for Disease Control and Prevention, and BMI was treated continuously.

\section{Analysis}

Data were analyzed using survival analysis with interval censoring in STATA version 11 using 5 data points (baseline and 4 annual follow-up visits). Weibull proportional hazard models were used to account for interval censoring, which adjusted for left and right censoring issues (given that some girls were pubertal at baseline and some were not pubertal by Year 5) and for censoring issues between visits (given that girls experienced pubertal onset at some unknown point between their annual visits). The effects of neighborhood factors on pubertal onset were examined for breast and pubic hair development, respectively, while adjusting for family income. Each neighborhood factor was examined separately. Interactive effects between neighborhood factors and ethnicity (Neighborhood Factor $\times$ Ethnicity) were included in each model separately. The mediating role of BMI was tested using the approach described by Baron and Kenny [41]. 
To control for hereditary factors, mother's age at menarche was considered as a covariate but was not significantly associated with either onset of breast $(\mathrm{HR}=1.0$ [0.97-1.03], $p=0.881)$ or pubic hair $(\mathrm{HR}=1.0$ [0.98-1.03], $p=0.795)$ development in bivariate analysis and remained non-significant even after adjusting for race and income. Therefore it was not included in subsequent analyses.

\section{Results}

Girls were 7.4 years old on average at baseline and ethnically diverse (Table 1). Twenty-two percent of families had annual household incomes below $\$ 50,000$ /year, which reflects the high cost of living in the San Francisco Bay Area. Overall, $5 \%$ of girls had experienced onset of breast development at baseline, and $77 \%$ by the $4^{\text {th }}$ follow-up visit (Table 2). For pubic hair development, $7 \%$ and $69 \%$ had onset at baseline and by $4^{\text {th }}$ follow-up exam, respectively. Consistent with national data, African American girls were more likely to exhibit breast and pubic hair onset at baseline compared to other ethnic groups; $10 \%$ had experienced breast onset and 20\% pubic hair onset. Asian girls were the least likely to have entered puberty at baseline and at $4^{\text {th }}$ follow-up exam. Average BMI was 17.2, and $30 \%$ of girls were "overweight" based on the CDC cutpoint ( $\geq 85^{\text {th }}$ percentile BMI by age). As expected, overweight girls were more likely to have experienced pubertal onset at younger ages compared to their non-overweight

Table 1 Descriptive characteristics of study participants ( $n=213$ )

\begin{tabular}{lrr}
\hline $\begin{array}{l}\text { Characteristic } \\
\text { Girls' Ethnicity }\end{array}$ & $\mathbf{n}$ & $\%$ \\
\hline Race/ethnicity & & \\
\hline African American & 51 & 23.9 \\
\hline Hispanic & 50 & 23.5 \\
\hline Asian & 23 & 10.8 \\
\hline White & 88 & 41.3 \\
\hline Other & 1 & 0.5 \\
\hline
\end{tabular}

\begin{tabular}{crr}
\hline Family income & 46 & 21.6 \\
\hline$<\$ 50,000$ & 167 & 78.4 \\
\hline$\geq \$ 50,000$
\end{tabular}

Girls' Overweight status (BMI $\geq 85$ th percentile for age)

\begin{tabular}{crr}
\hline Not overweight & 149 & 70.0 \\
\hline Overweight & 64 & 30.0 \\
\hline & mean & range \\
\hline Age at baseline (in years) & 7.4 & $6.5-8.1$ \\
\hline Age of birth mother & 40.0 & $22.0-$ \\
& & 54.0 \\
\hline Girls' weight in kg & 27.2 & 16.8 \\
& & 57.3 \\
\cline { 2 - 3 } Girls' body mass index (BMI) & 17.23 & $12.2-$ \\
& & 29.0 \\
\hline
\end{tabular}

Table 2 Breast and pubic hair onset at baseline and by follow-up $4(n=213)$

\begin{tabular}{|c|c|c|c|c|c|}
\hline & \multirow[b]{3}{*}{$\mathrm{N}$} & \multicolumn{4}{|c|}{$\begin{array}{c}\text { Number with breast/pubic hair } \\
\text { onset }\end{array}$} \\
\hline & & \multicolumn{2}{|c|}{ At baseline } & \multicolumn{2}{|c|}{ At follow-up 4} \\
\hline & & $\mathrm{n}$ & $\%$ & $\mathrm{n}$ & $\%$ \\
\hline Breast Onset & 213 & 11 & 5.2 & 164 & 77.0 \\
\hline \multicolumn{6}{|l|}{ By race/ethnicity } \\
\hline African American & 51 & 5 & 9.8 & 45 & 88.2 \\
\hline Hispanic & 50 & 4 & 8.0 & 40 & 80.0 \\
\hline Asian & 23 & 0 & 0.0 & 18 & 78.3 \\
\hline White & 88 & 2 & 2.3 & 61 & 69.3 \\
\hline Other & 1 & 0 & 0.0 & 0 & 0.0 \\
\hline \multicolumn{6}{|c|}{ By baseline weight } \\
\hline Not overweight & 149 & 3 & 2.0 & 108 & 72.5 \\
\hline Overweight $^{a}$ & 64 & 8 & 12.5 & 56 & 87.5 \\
\hline Pubic hair onset & 213 & 15 & 7.0 & 146 & 68.5 \\
\hline \multicolumn{6}{|l|}{ By race/ethnicity } \\
\hline African American & 51 & 10 & 19.6 & 43 & 84.3 \\
\hline Hispanic & 50 & 2 & 4.0 & 38 & 76.0 \\
\hline Asian & 23 & 0 & 0.0 & 13 & 56.5 \\
\hline White & 88 & 3 & 3.4 & 52 & 59.1 \\
\hline Other & 1 & 0 & 0.0 & 0 & 0.0 \\
\hline \multicolumn{6}{|c|}{ By baseline weight } \\
\hline Not overweight & 149 & 6 & 4.0 & 96 & 64.4 \\
\hline Overweight $^{a}$ & 64 & 9 & 14.1 & 50 & 78.1 \\
\hline
\end{tabular}

${ }^{\text {a Based on }} \geq 85^{\text {th }}$ percentile as established by the CDC

peers. Of those who were overweight at baseline $(n=64)$, $88 \%$ had breast onset and $78 \%$ pubic hair onset by the $4^{\text {th }}$ follow-up exam compared to $73 \%$ and $64 \%$ of non-overweight girls, respectively (Table 2).

Unadjusted (bivariate) analyses (Table 3) indicated marginal associations between breast onset and "Mixed and Commercial Land Use" (HR = 1.04, $p=.09)$, "Recreation" $(\mathrm{HR}=0.9, p=.07)$ and "Disorder" ( $\mathrm{HR}=1.15, p=.08)$. Higher BMI $(1.09, p<0.01)$, African American ethnicity $(\mathrm{HR}=2.53, p<0.01)$ and low household income $(\mathrm{HR}=$ $1.82, p=0.002)$ at baseline were significantly associated with increased rates of breast onset. "Recreation" was significantly associated with delayed onset of pubic hair $(\mathrm{HR}=0.88, p=0.03)$, while higher $\mathrm{BMI}(\mathrm{HR}=1.09, p<$ $0.01)$, low household income $(\mathrm{HR}=2.10, p<0.01)$, and African American ethnicity ( $\mathrm{HR}=2.99, p<0.01)$ were associated with increased rates of pubic hair onset.

In multivariable analysis, after controlling for ethnicity and family income, only "Recreation" remained marginally associated with breast development (Table 4). When BMI was adjusted for in the model, Recreation was significantly associated with delayed breast onset $(\mathrm{HR}=0.89, p=0.03)$. There were no main effects for neighborhood factors with regard to onset of pubic hair development. 
Table 3 Unadjusted, bivariate associations between neighborhood and demographic characteristics and pubertal onset $(n=213)$

\begin{tabular}{lrrrrr}
\hline & Breast Onset & \multicolumn{3}{c}{ Pubic Hair Onset } \\
& Hazard Rate & $\boldsymbol{p}$ & Hazard Rate & $\boldsymbol{p}$ \\
\hline Neighborhood factors & & & & & \\
\hline Mixed land use & 1.04 & .09 & 1.02 & .45 \\
\hline Food and retail & 1.01 & .70 & 0.98 & .55 \\
\hline Recreation Outlets & 0.90 & .07 & 0.88 & .03 \\
\hline Walkability & 0.94 & .34 & 0.94 & .30 \\
\hline Disorder & 1.15 & .08 & 1.04 & .60 \\
\hline Body Mass Index & 1.09 & $<.01$ & 1.09 & $<.01$ \\
\hline Low income(< $\$ 50,000)$ & 1.82 & $<.01$ & 2.10 & $<.01$ \\
\hline Ethnicity & & & & \\
\hline African American & 2.53 & $<.01$ & 2.99 & $<.01$ \\
\hline Hispanic & 1.33 & .18 & 1.43 & .10 \\
\hline Asian & 1.22 & .48 & 0.64 & .16 \\
\hline Other & 0.00 & 1.00 & & \\
\hline White & ref & & ref & \\
\hline
\end{tabular}

In multivariable analyses including neighborhood factor $x$ ethnicity interaction terms, Recreation $\times$ Ethnicity was significant for both timing of breast and pubic hair development (Table 5). Interaction terms for other neighborhood factors were not significant. After adjusting for BMI, stratified analyses (Table 6) showed that Recreation was significantly associated with timing of breast onset and pubic hair onset for African American girls only. There were no significant effects in other ethnic groups.

To test the potential mediating role of BMI in the relationship between Recreation and pubertal outcomes for African Americans, we first examined the direct association between Recreation and BMI by ethnic group (Table 7). After controlling for family income, Recreation was not significantly associated with BMI, indicating that BMI was not in the causal path between Recreation and pubertal onset. We also compared the effects of Recreation on breast and pubic hair onset with and without adjusting for BMI. The effects of Recreation on the two pubertal outcomes persisted when BMI was included in the models.

\section{Discussion}

This investigation examined the influence of girls' neighborhood environments on their timing of onset of breast and pubic hair development, while taking into consideration BMI, family income and ethnicity. Consistent with past studies, African American girls, those from lower income families, and girls with higher BMI were at greatest risk for experiencing breast development at younger ages. Asian girls and those with lower BMI were at reduced risk for experiencing pubertal onset at younger ages.
We found that African American girls who lived in neighborhoods characterized as having more recreational outlets (Recreation) experienced lower rates of onset of breast and pubic hair development over the 4 years of follow-up of our study, i.e., by ages 10-12 years. For each one-unit increase in the neighborhood Recreation index, African American girls experienced a 26\% and $28 \%$ decrease in hazard rates for breast and pubic hair onset, respectively. The Recreation index included neighborhood factors such as availability of parks, walking or hiking trails, playing fields, and basketball or tennis courts. These results suggest that physical activity may play a key role in determining accelerated onset of breast and pubic hair development among young African American girls. There were no significant neighborhood effects on pubertal development among girls from other ethnic groups. Therefore, the availability of recreational outlets may be particularly important for African Americans. Further investigation to better understand these ethnic-specific effects is warranted.

Being overweight is a well-established risk factor for early entrance into puberty, and hormonal mechanisms related to adiposity are likely to explain the relationship between BMI and pubertal acceleration [9,15,34]. Although girls' overweight was strongly predictive of timing of pubertal onset in our sample, we did not find evidence that BMI mediated the association (was in the causal pathway) between the recreational environment and pubertal timing for African American girls. In fact, there was no significant association between Recreation and BMI, neither in bivariate (unadjusted) tests nor after adjusting for family income. Rather, the effect of Recreation on pubertal outcomes was independent of the effect of BMI. A number of rigorous epidemiological studies, however, have found direct associations between neighborhood availability of recreational outlets and overweight. For example, a recent study using data from the National Survey of Children's Health, found that children living in environments with no parks, playgrounds, recreation or community centers were at higher odds for experiencing obesity, and that neighborhood effects were more pronounced among younger children (10-11 years old) and among girls [30]. This study also illustrated clear ethnic and socioeconomic disparities in overweight among children, with ethnic minority youth and those in poverty showing the highest rates of obesity and overweight [30]. It is likely that these girls were at elevated risk for early puberty as well, although pubertal outcomes were not investigated. Other studies have also shown marked disparities in neighborhood access to physical activity facilities, with lower socioeconomic and high-density minority neighborhoods having fewer recreational outlets, and residents in these neighborhoods, in turn, exhibiting 
Table 4 Adjusted associations of neighborhood factors and pubertal outcomes $(n=213)$

\begin{tabular}{|c|c|c|c|c|}
\hline \multirow[t]{2}{*}{ Neighborhood Variable } & \multicolumn{2}{|c|}{ Before adjusting for BMI } & \multicolumn{2}{|c|}{ After adjusting for BMI } \\
\hline & $\mathrm{HR}(95 \% \mathrm{Cl})$ & $p$-value & $\mathrm{HR}(95 \% \mathrm{Cl})$ & $p$-value \\
\hline \multicolumn{5}{|l|}{ Breast onset } \\
\hline Mixed land use & $1.01(0.97-1.06)$ & 0.54 & $1.01(0.96-1.06)$ & 0.67 \\
\hline $\mathrm{BMI}$ & & & $1.09(1.03-1.15)$ & $<0.01$ \\
\hline Food and retail & $1.01(0.94-1.08)$ & 0.87 & $1.01(0.94-1.08)$ & 0.75 \\
\hline $\mathrm{BMI}$ & & & $1.09(1.03-1.15)$ & $<0.01$ \\
\hline Walkability & $0.93(0.82-1.06)$ & 0.30 & $0.91(0.8-1.04)$ & 0.18 \\
\hline $\mathrm{BMI}$ & & & $1.09(1.04-1.15)$ & $<0.01$ \\
\hline Recreation & $0.91(0.82-1.01)$ & 0.09 & $0.89(0.79-0.99)$ & 0.03 \\
\hline $\mathrm{BMI}$ & & & $1.1(1.04-1.16)$ & $<0.01$ \\
\hline Disorder & $1.09(0.91-1.29)$ & 0.35 & $1.06(0.89-1.27)$ & 0.51 \\
\hline $\mathrm{BMI}$ & & & $1.09(1.03-1.15)$ & $<0.01$ \\
\hline \multicolumn{5}{|l|}{ Pubic hair onset } \\
\hline Mixed land use & $0.98(0.94-1.03)$ & 0.49 & $0.98(0.94-1.03)$ & 0.54 \\
\hline $\mathrm{BMI}$ & & & $1.08(1.02-1.15)$ & 0.01 \\
\hline Food and retail & $0.97(0.9-1.05)$ & 0.43 & $0.98(0.91-1.05)$ & 0.54 \\
\hline $\mathrm{BMI}$ & & & $1.08(1.02-1.14)$ & 0.01 \\
\hline Walkability & $0.89(0.78-1.02)$ & 0.09 & $0.90(0.78-1.03)$ & 0.11 \\
\hline BMI & & & $1.08(1.02-1.14)$ & 0.01 \\
\hline Recreation & $0.89(0.79-1.01)$ & 0.06 & $0.91(0.81-1.03)$ & 0.12 \\
\hline $\mathrm{BMI}$ & & & $1.08(1.02-1.14)$ & 0.01 \\
\hline Disorder & $0.97(0.82-1.15)$ & 0.72 & $0.95(0.8-1.14)$ & 0.60 \\
\hline $\mathrm{BMI}$ & & & $1.08(1.03-1.15)$ & $<0.01$ \\
\hline
\end{tabular}

All models were adjusted for ethnicity and income

decreased physical activity levels and increased overweight [32].

Our findings provide preliminary evidence that neighborhood availability of recreational outlets, which signal opportunities for increased engagement in physical activity and reduced sedentary activity, influence African American girls' pubertal timing. Although body composition assessed using BMI is clearly an important determinant of pubertal timing, physical activity levels and/or sedentary behaviors may act as more proximal, and

Table 5 Adjusted associations between Recreation and pubertal outcomes, including Recreation $\times$ ethnicity interaction term $(n=213)$

\begin{tabular}{|c|c|c|c|c|c|c|}
\hline \multirow[b]{2}{*}{ Variable } & \multicolumn{3}{|c|}{ Breast Onset } & \multicolumn{3}{|c|}{ Pubic Hair Onset } \\
\hline & Coef & HR & $p$-value & Coef & HR & $p$-value \\
\hline Recreation & 0.05 & 1.05 & 0.611 & 0.09 & 1.09 & 0.387 \\
\hline Low income $(<\$ 50,000)$ & 0.38 & 1.46 & 0.137 & 0.64 & 1.90 & 0.012 \\
\hline $\mathrm{BMI}$ & 0.10 & 1.11 & 0.000 & 0.08 & 1.08 & 0.006 \\
\hline \multicolumn{7}{|l|}{ Ethnicity } \\
\hline African American & 1.17 & 3.23 & 0.000 & 1.50 & 4.49 & 0.000 \\
\hline Hispanic & 0.20 & 1.22 & 0.533 & 0.00 & 1.00 & 0.995 \\
\hline Asian & 0.52 & 1.68 & 0.146 & -0.01 & 0.99 & 0.986 \\
\hline White & ref & & & ref & & \\
\hline Recreation $\times$ African American & -0.33 & 0.72 & 0.035 & -0.44 & 0.64 & 0.010 \\
\hline Recreation $\times$ Hispanic & -0.23 & 0.80 & 0.127 & -0.11 & 0.89 & 0.459 \\
\hline Recreation $\times$ Asian & -0.15 & 0.86 & 0.396 & -0.36 & 0.70 & 0.126 \\
\hline Recreation $\times$ White & ref & & & ref & & \\
\hline
\end{tabular}


Table 6 Adjusted associations of Recreation and pubertal outcomes by race $(n=213)$

\begin{tabular}{|c|c|c|c|c|}
\hline \multirow[t]{2}{*}{ Subgroup } & \multicolumn{2}{|c|}{ Before adjusting for BMI } & \multicolumn{2}{|c|}{ After adjusting for BMI } \\
\hline & $\mathrm{HR}(95 \% \mathrm{Cl})$ & p-value & $\mathrm{HR}(95 \% \mathrm{Cl})$ & $\mathrm{p}$-value \\
\hline \multicolumn{5}{|l|}{ Breast onset } \\
\hline African American & $0.83(0.65-1.04)$ & 0.106 & $0.74(0.56-0.97)$ & 0.032 \\
\hline Hispanic & 0.86(0.68-1.09) & 0.208 & 0.87(0.68-1.10) & 0.229 \\
\hline Asian & $0.92(0.68-1.24)$ & 0.584 & $0.88(0.66-1.18)$ & 0.402 \\
\hline White & $1.07(0.88-1.30)$ & 0.488 & $1.06(0.88-1.29)$ & 0.534 \\
\hline \multicolumn{5}{|l|}{ Pubic hair onset } \\
\hline African American & $0.75(0.58-0.96)$ & 0.022 & $0.72(0.55-0.94)$ & 0.015 \\
\hline Hispanic & $0.84(0.67-1.05)$ & 0.125 & 0.86(0.68-1.09) & 0.217 \\
\hline Asian & $0.75(0.49-1.15)$ & 0.190 & $0.74(0.47-1.16)$ & 0.189 \\
\hline White & $1.10(0.90-1.34)$ & 0.368 & $1.10(0.90-1.34)$ & 0.364 \\
\hline
\end{tabular}

potentially modifiable, explanatory factors that influence the relationship between neighborhood environment and pubertal timing. As such, neighborhood recreation outlets may serve as important protective factors for young African American girls during this developmental period. Future studies should delve deeper to assess girls' utilization of neighborhood recreational facilities, and their relative activity levels, to determine whether subjective and objective measures of physical activity account for the relationship between availability of recreation facilities and timing of breast development. It may also be important to consider whether availability of recreational outlets and physical activity levels interact with African American girls' overweight to influence pubertal onset (e.g., are effects greater for overweight girls?). Finally, our findings suggest that further exploration of hormonal mechanisms is critical in order to better understand whether physical activity might counteract or ameliorate the accelerating effects of overweight and adiposity on girls' pubertal development.

\section{Limitations}

This investigation included data from the first five annual clinic visits of an ongoing prospective study. At $4^{\text {th }}$ follow-up, $23 \%$ of girls had not yet experienced breast onset, and about $32 \%$ had not experienced onset of pubic hair development. As a result, we were not able to capture later pubertal onset (or delayed puberty) nor were girls old enough to allow for the examination of menarche. We were also unable to assess the rate at which girls progressed through puberty, also known as pubertal tempo, given the girls' ages. As girls in the sample grow older, we will be able to examine these outcomes. Neighborhood characteristics were defined geographically, based on audits conducted within a quarter-mile radius of the block containing the girls' residences. While findings showed significant effects of the recreational environment immediately surrounding a girl's residence, the environment that a girl may frequent outside of this circumscribed area (e.g., access to recreation in the school environment) was not accounted for in this investigation and may have contributed to the ethnic differences in our findings. Moreover, the relatively small sample size may have limited our power to detect interactions between ethnicity and other neighborhood factors; however, this also lends confidence to our significant interactive findings for African American girls. Finally, other contextual and familial factors that are known to influence pubertal timing, such as family composition and childhood sexual

Table 7 Association between neighborhood factors and BMI by Ethnicity $(n=213$ )

\begin{tabular}{lcccccrrrr}
\hline & African American & Hispanic & & Asian & & White \\
\hline & Coef & $\boldsymbol{p}$-value & Coef & $\boldsymbol{p}$-value & Coef & $\boldsymbol{p}$-value & Coef & $\boldsymbol{p}$-value \\
\hline Mixed land use & 0.13 & 0.34 & 0.01 & 0.94 & -0.05 & 0.58 & 0.01 & 0.84 \\
\hline Food and retail & 0.36 & 0.12 & -0.01 & 0.97 & -0.07 & 0.47 & -0.06 & 0.57 \\
\hline Recreation & 0.05 & 0.90 & -0.31 & 0.43 & 0.07 & 0.74 & -0.07 & 0.66 \\
\hline Walkability & -0.16 & 0.74 & 0.20 & 0.63 & -0.34 & 0.30 & 0.08 & 0.61 \\
\hline Disorder & 1.22 & 0.04 & -0.50 & 0.43 & -0.24 & 0.44 & 0.37 & 0.06 \\
\hline
\end{tabular}

All models were adjusted for income 
abuse, were beyond the scope of the current study but are important determinants of physical health and mental health over the life course.

This study had considerable strengths. Tanner stage assessments for pubertal onset were conducted using clinical examination by trained clinic staff based on standardized methods, which is considered the gold standard in the field [13]. Potential misclassification of breast development due to adiposity was minimized in this study as palpation and visual inspection were both utilized to assess onset of breast development. Assessment of height and weight to calculate BMI was conducted in clinic using standardized and reliable measurement tools. In addition, we employed direct inperson observations to assess neighborhood environments rather than relying on aggregate measures such as those available from census tract data.

\section{Conclusions}

This is the first known study to prospectively examine the effects of a girl's neighborhood environment on her pubertal timing. As such, this study represents an initial step towards understanding the potentially complex effects of various neighborhood level factors on pubertal maturation. Results demonstrated that availability of recreational outlets was significantly related to timing of breast and pubic hair development for African American girls, even when strong predictors of puberty such as income and BMI were considered. While all normallydeveloping girls experience puberty, early timing of pubertal onset contributes to both short-term health consequences in adolescence and risk for longer-term negative health outcomes among women, including obesity, breast and other reproductive cancers, and cardiovascular disease. Moreover, physical activity is a known protective factor for many of these health outcomes in adulthood [42-44]. As such, a better understanding of how neighborhood factors, particularly opportunities for physical activity, influence girls' pubertal timing may inform successful intervention strategies and policy development to promote better health over the life course for women.

\footnotetext{
Abbreviations

BMI: Body mass index; HPG axis: Hypothalamic-pituitary-gonadal axis; HPA axis: Hypothalamic-pituitary-adrenal axis; NIEHS: National institute of environmental health sciences; NCl: National cancer institute; CYGNET: Cohort study of young girls' nutrition, environment, and transitions; KPNC: Kaiser permanente northern california
}

\section{Acknowledgements}

This publication was supported by Grant UL1 RR024131 from the NIH, and Grant 14NB-0173 from the California Breast Cancer Research Program. Its contents are solely the responsibility of the authors and do not necessarily represent the official views of the NIH or the California Breast Cancer Research Program.
The authors thank the participants and staff of the CYGNET Study; Louise Swig, David Burian and Anja Simms for collection of street audit data; and Anousheh Mirabedi, Cecile Laurent, Josh Ergas, and Dana Nickleach for data support.

\section{Author details}

${ }^{1}$ School of Public Health, University of California, Berkeley, CA, USA. ${ }^{2}$ Division of Research, Kaiser Permanente Northern California, Oakland, CA, USA.

${ }^{3}$ School of Medicine, University of California, San Francisco, CA, USA.

\section{Authors' contributions}

JD took the lead in conceptualizing this paper, was involved in pubertal data collection and clinic interviews, developed the analytic plan, interpreted the findings and wrote the majority of the paper. MF conducted the literature review, helped conceptualize the study, conducted preliminary analyses, and drafted portions of the paper. JPE conducted the majority of the analyses, contributed to writing the results section and created the tables. LK designed the study, oversaw collection of pubertal and demographic data, contributed conceptually to the paper, and provided edits. LG oversaw the Tanner staging methodology, ensured the quality of the pubertal data, contributed conceptually to the paper, and provided edits. IY conceived the study, contributed to study design, oversaw collection of the neighborhood data, contributed conceptually to this paper, and drafted portions of the paper. All authors read and approved the final manuscript.

\section{Competing interests}

The authors declare that they have no competing interests.

Received: 20 October 2011 Accepted: 13 March 2012

Published: 13 March 2012

\section{References}

1. Adair $L S$, Gordon-Larsen P: Maturational timing and overweight prevalence in US adolescent girls. Am J Public Health 2001, 91:642-644.

2. Ge X, Conger RD, Elder GH Jr: Coming of age too early: pubertal influences on girls' vulnerability to psychological distress. Child Dev 1996, 67:3386-3400.

3. Caspi A, Lynam D, Moffitt TE, Silva PA: Unraveling girls' delinquency: Biological, dispositional, and contextual contributions to adolescent misbehavior. Dev Psychol 1993, 29:19-30.

4. Dick DM, Rose RJ, Viken RJ, Kaprio J: Pubertal timing and substance use: associations between and within families across late adolescence. Dev Psychol 2000, 36:180-189.

5. Deardorff J, Gonzales NA, Christopher FS, Roosa MW, Millsap R: Early puberty and adolescent pregnancy: the influence of alcohol use. Pediatrics 2005, 116(6):1451-1456.

6. Bernstein L: Epidemiology of endocrine-related risk factors for breast cancer. J Mammary Gland Biol Neoplasia 2002, 7(1):3-15.

7. Vo C, Carney M: Ovarian cancer hormonal and environmental risk. Obstet Gynecol Clin N Am 2007, 34:687-700.

8. Parent AS, Teilmann G, Juul A, Skakkebaek NE, Toppari J, Bourguignon JP: The timing of normal puberty and the age limits of sexual precocity: variations around the world, secular trends, and changes after migration. Endocr Rev 2005, 24(5):668-693.

9. Gluckman PD, Hanson MA: Evolution, development and timing of puberty. Trends Endocrinol Metab 2006, 17(1):7-12.

10. Chumlea WC, Schubert CM, Roche AF, Kulin HE, Lee PA, Himes JH, Sun SS: Age at menarche and racial comparisons in US girls. Pediatrics 2003, 111(1):110-113.

11. Euling SY, Herman-Giddens ME, Lee PA, Selevan SG, Juul A, Sorenson T, Dunkel L, Himes JH, Teilmannm G, Swan SH: Examination of US pubertytiming data from 1940 to 1994 for secular trands: panel findings. Pediatrics 2008, 121(3):S172-S191.

12. Sun SS, Schubert CM, Chumlea WC, Roche AF, Kulin HE, Lee PA, Himes JH, Ryan AS: National estimates of the timing of sexual maturation and racial differences among US children. Pediatrics 2002, 110(5):911-919.

13. Biro FM, Galvez MP, Greenspan LC, Succop PA, Vangeepuram N, Pinney SM, Teitelbaum S, Windham GC, Kushi LH, Wolf fMS: Pubertal assessment method and baseline characteristics in a mixed longitudinal study of girls. Pediatrics 2010, 126(3):583-590. 
14. Ellis BJ: Timing of pubertal maturation in girls: An integrated life history approach. Psychol Bull 2004, 130(6):920-958,

15. Lee JM, Appugliese D, Kaciroti N, Corwyn RF, Bradley RH, Lumeng JC: Weight status in young girls and the onset of puberty. Pediatrics 2007, 119(3):624-630.

16. Belsky J, Houts RM, Fearon RMP: Infant attachment security and the timing of puberty: testing an evolutionary hypothesis. Psychol Science 2010, 21(9):1195-1201.

17. Belsky J, Steinberg L, Houts RM, Halpern-Felsher BL: The development of reproductive strategy in females: early maternal harshness, earlier menarche, increased sexual risk taking. Dev Psychol 2010, 46(1):120-128.

18. Deardorff J, Kushi LH, Ekwaru JP, Ellis BJ, Greenspan LC, Mirabedi A, Landaverde EG, Hiatt RA: Father absence, BMI, and pubertal timing in girls: differential effects by income and ethnicity. J Adolesc Health 2011, 48(5):441-447.

19. Ellis BJ, Shirtcliff EA, Boyce WT, Deardorff J, Essex MJ: Quality of early family relationships and the timing and tempo of puberty: effects depend on biological sensitivity to context. Dev Psychopathol 2011, 23:85-99.

20. Wolff MS, Teitelbaum SL SMP, Windham G, Liao L, Biro F, Kushi LH, Erdmann C, Hiatt RA, Rybak ME, et al: Investigation of relationships between urinary biomarkers of phytoestrogens, phthalates, and phenols and pubertal stages in girls. Environ Health Perspect 2010, 118(7):1039-1046.

21. Frumkin H: Healthy places: exploring the evidence. Am J Public Health 2003, 93(9):1451-1456.

22. Buka SL, Brennan RT, Rich-Edwards JW, Raudenbush SW, Earls F: Neighborhood support and the birth weight of urban infants. Am J Epidemiol 2003, 157(1):1-8.

23. Juhn YJ, Sauver JS, Katusic S, Vargas D, Weaver A, Yunginger J: The influence of neighborhood environment on the incidence of childhood asthma: a multilevel approach. Soc Sci Med 2005, 60(11):2453-2464.

24. Sargent JD, Brown MJ, Freeman JL, Bailey A, Goodman D, Freeman DH Jr: Childhood lead poisoning in Massachusetts communities: its association with sociodemographic and housing characteristics. Am J Public Health 1995, 85(4):528-534.

25. Carver A, Timperio A, Crawford D: Playing it safe: the influence of neighbourhood safety on children's physical activity. A review. Health Place 2008, 14(2):217-227

26. Dodson J, Hsiao Y, Kasat-Shors M, Murray L, Nguyen NK, Richards AK, Gittelsohn J: Formative Research for a Healthy Diet Intervention Among Inner-City Adolescents: The Importance of Family, School and Neighborhood Environment. Ecol Food Nutr 2009, 48(1):39-58.

27. Timperio A, Ball K, Roberts R, Campbell K, Andrianopoulos N, Crawford D: Children's fruit and vegetable intake: associations with the neighbourhood food environment. Prev Med 2008, 46(4):331-335.

28. Biro FM, Wolff MS, Kushi LH: Impact of yesterday's genes and today's diet and chemicals on tomorrow's women. J Pediatr Adolesc Gynecol 2009, 22(1):3-6.

29. Goran Ml, Gower BA, Nagy TR, Johnson RK: Developmental changes in energy expenditure and physical activity in children: evidence for a decline in physical activity in girls before puberty. Pediatrics 1998 101(5):887-891.

30. Singh GK, Siahpush M, Kogan MD: Neighborhood and socioeconomic conditions, built environments, and childhood obesity. Health Affairs 2010, 29(3):503-512.

31. Papas MA, Alberg AJ, Ewing R, Helzlsouer KJ, Gary TL, Klassen AC: The built environment and obesity. Epidemiol Rev 2007, 29:129-143.

32. Gordon-Larsen P, Nelson MC, Page P, Popkin BM: Inequality in the built environment underlies key health disparities in physical activity and obesity. Pediatrics 2006, 117:417-424.

33. Biro F, Huang B, Morrison JA, Horn PS, Daniels SR: Body mass index and waist-to-height changes during teen years in girls are influenced by childhood body mass index. J Adolesc Health 2010, 46:245-250.

34. Biro FM, Khoury P, Morrison JA: Influence of obesity on timing of puberty. Int J Androl 2006, 29:272-277.

35. Shirtcliff EA, Dahl RE, Pollak SD: Pubertal development: correspondence between hormonal and physical development. Child Dev 2009, 80:327-333.

36. Hiatt RA, Haslam S, Osuch J: The Breast Cancer and the Environment Research Centers: transdisciplinary research on the role of the environment in breast cancer etiology. Env Hlth Perspective 2009, 117:1814-1822.

37. Leung CW, Gregorich SE, Laraia BA, Kushi LH, Yen IH: Measuring the neighborhood environment: associations with young girls' energy intake and expenditure in a cross-sectional study. Int J Behav Nutr Phys Act 2010, 7:52.

38. Morris NM, Udry JR: Validation of a self-administered instrument to assess stage of adolescent development. J Youth Adolesc 1980, 9(3):271-280

39. Udry JR, Cliquet RL: A cross-cultural examination of the relationship between ages at menarche, marriage, and first birth. Demography 1982, 19:53-63.

40. Brownson RC, Hoehner CM, Brennan LK, Cook RA, Elliott MB, McMullen KM: Reliability of 2 Instruments for Auditing the Environment for Physical Activity. J Phys Act Health 2004, 1:191-208.

41. Baron RM, Kenny DA: The moderator-mediator variable distinction in social psychological research: Conceptual, strategic, and statistical considerations. J Pers Soc Psychol 1986, 51(6):1173-1182.

42. Friedenreich CM: Physical activity and breast cancer: review of the epidemiologic evidence and biologic mechanisms. Recent Results Cancer Res 2011, 188:125-139.

43. Lynch BM, Friedenreich CM, Winkler EA, Healy GN, Vallance JK, Eakin EG, Owen N: Associations of objectively assessed physical activity and sedentary time with biomarkers of breast cancer risk in postmenopausal women: findings from NHANES (2003-2006). Breast Cancer Res Treat 2011, 130(1):183-94, Epub 2011 May 8.

44. Oguma Y, Shinoda-Tagawa T: Physical activity decreases cardiovascular disease risk in women: review and meta-analysis. Am J Prev Med 2044, 26(5):407-418

\section{Pre-publication history}

The pre-publication history for this paper can be accessed here: http://www.biomedcentral.com/1471-2431/12/27/prepub

doi:10.1186/1471-2431-12-27

Cite this article as: Deardorff et al:: Does neighborhood environment influence girls' pubertal onset? findings from a cohort study. BMC Pediatrics 2012 12:27.

\section{Submit your next manuscript to BioMed Central and take full advantage of:}

- Convenient online submission

- Thorough peer review

- No space constraints or color figure charges

- Immediate publication on acceptance

- Inclusion in PubMed, CAS, Scopus and Google Scholar

- Research which is freely available for redistribution

Submit your manuscript at www.biomedcentral.com/submit
C Biomed Central 